\title{
Spatio-temporal patterns in diversity of a fish assemblage along the Norwegian Skagerrak coast
}

\author{
Kyrre Lekve $^{1}$, Nils Chr. Stenseth ${ }^{1, *}$, Jakob Gjøsater $^{2}$, Jean-Marc Fromentin ${ }^{3}$, \\ John S. Gray ${ }^{4}$ \\ 'University of Oslo, Department of Biology, Division of Zoology, PO Box 1050 Blindern, N-0316 Oslo, Norway \\ ${ }^{2}$ Institute of Marine Research, Flødevigen Marine Research Station, N-4817 His, Norway \\ ${ }^{3}$ IFREMER, 1 rue Jean Vilar, BP 171, F-34203 Sète Cedex, France \\ ${ }^{4}$ University of Oslo, Department of Biology, Division of Marine Biology and Chemistry, PO Box 1050 Blindern, N-0316 Oslo, \\ Norway
}

\begin{abstract}
Time series from 1953 to 1997 of 34 fish species sampled by beach seine at 69 stations along the Norwegian Skagerrak coast were analysed to describe spatial patterns of temporal variation in species richness and diversity. Principal Components Analyses were performed on species richness, total abundance and the Shannon diversity index. Spatially consistent temporal variation was detected on a scale exceeding that of the individual fjords. Two main spatial patterns were detected: one for the open Skagerrak, which showed large temporal variability with a decrease in the number of species for most of the study period followed by a recovery in the number of species, and another for the Oslofjord area, which did not show a recovery in the number of species. The total abundance and the Shannon diversity index for the same data set failed to reveal these spatial patterns. Underlying processes that might be related to the spatio-temporal variation of the fish assemblage, especially eutrophication and industrial pollution, and climatic changes are discussed.
\end{abstract}

KEY WORDS: Species richness · Principal Components Analysis · Eutrophication · Oslofjord

\section{INTRODUCTION}

The shallow coastal zone is an important nursery ground for several fish species, many of them having commercial value (Bøhle 1993, Botsford et al. 1997). At a local scale, tidal effects (Rangeley \& Kramer 1995), complexity of habitat (Tupper \& Boutilier 1995) and competition (Gjøsæter 1988, Fromentin et al. 1997b) have been shown to influence the distribution of coastal fish species (for reviews, see Gibson 1982, Wootton 1990). Along the Norwegian Skagerrak coast anthropogenic effects such as pollution (Ruud 1968, Nash 1985, Johannessen \& Dahl 1996) and the effects of coastal currents (Bøhle 1993) also have been shown to influence the distribution of the fish species. At an even

- Addressee for correspondence.

E-mail: n.c.stenseth@bio.uio.no larger scale, climatic changes may affect species diversity significantly (Dickson 1971, Dickson et al. 1994).

In order to understand ecological processes causing changes in natural communities, processes must be studied at the appropriate scales, both spatially and temporally (Wiens 1989). At small scales, patterns might be blurred by local heterogeneity and biological interactions, weakening the link to physical prossesses. At large scales, generalisations can more easily be made and predictability is greater, as effects of local heterogeneity are averaged out (Wiens 1989).

The scale of processes affecting fish assemblages is unclear (Clarke \& Green 1988, Sale 1988). However, at the species level Fromentin et al. (1997b, 1998) found that temporal fluctuations of abundance of cod and pollack along the Norwegian Skagerrak coast could be divided mainly into short-term cycles and long-term trends. 


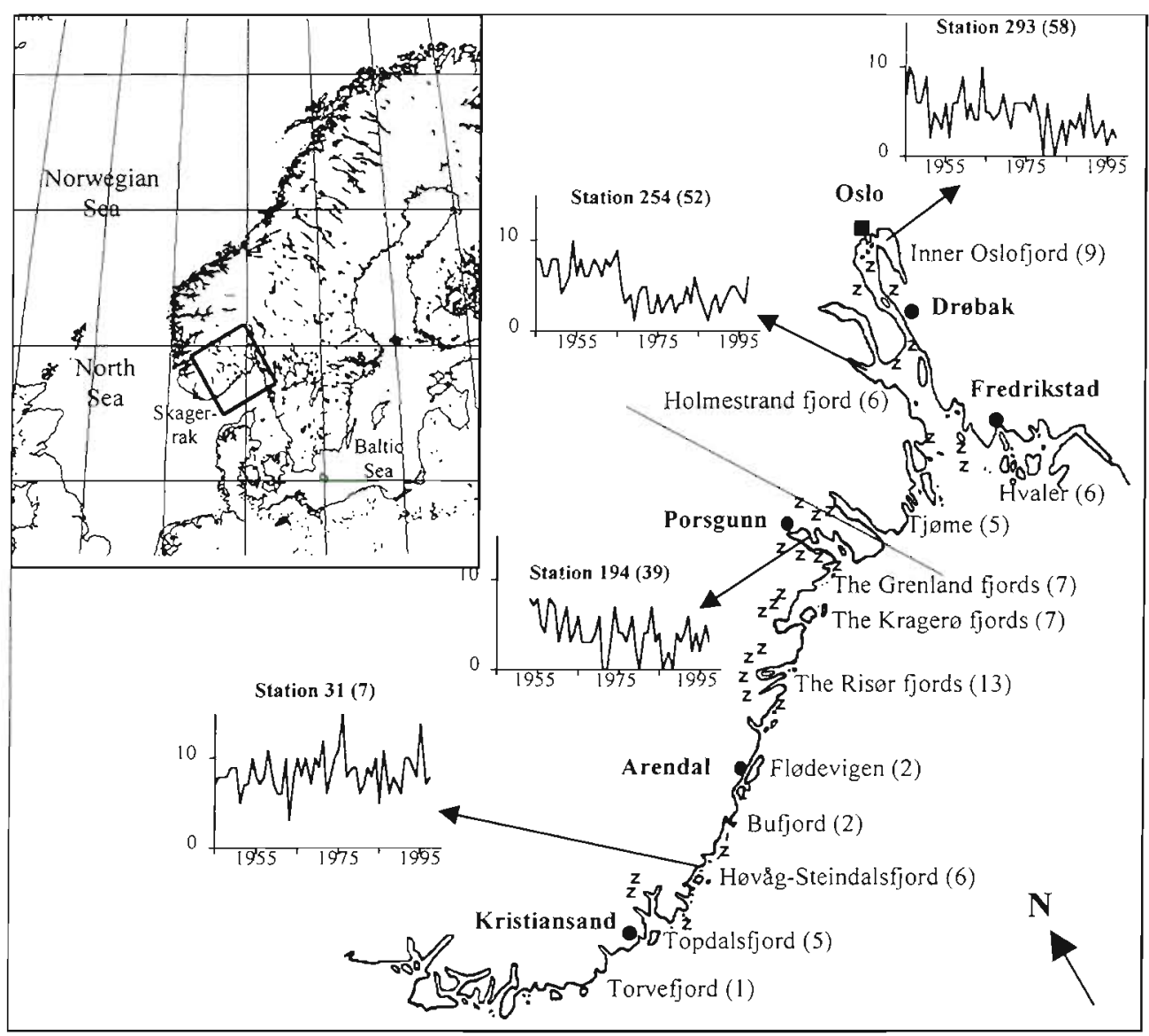

Fig. 1. General location of the sampling stations along the Norwegian coast (upper left-hand corner). Coastline in detail (lower right) showing fjords or areas where the 69 sampling stations were located. (Number of stations at each location given in parentheses.) The time series (based on data from 69 stations) were obtained from an extensive research survey, the 'Flødevigen data set', conducted from 1953 to 1997. ' $z$ ' indicates the 27 hydrographic sampling sites, running from 1953 to 1994. The gray diagonal line separates the Oslofjord area and the rest of the coast. Time series insets for Stns 293, 254, 194 and 31 (permanent station numbers) show raw data for number of species (station numbers used in our study given in parentheses)

Here we report results of temporal and spatial studies from a number of time series on fish species and environmental measurements from the shallow coastal zone along the Norwegian Skagerrak coast. Long-term surveys (more than $40 \mathrm{yr}$ ) of fish populations are scarce and we show here how historical data can provide interesting information which is useful for understanding long-term variability of coastal fish assemblages.

\section{MATERIALS AND METHODS}

Study area. In 1919, a monitoring program was initiated along the southern part of the Norwegian Skagerrak coast in order to study the effect of cod enhancement experiments involving the large-scale release of young fish (Tveite 1971, Johannessen \& Sollie 1994, Fromentin et al. 1997b, see also Fig. 1). The program was extended to the Oslofjord area (Holmestrand,
Tjome, Hvaler and the Inner Oslofjord, see Fig. 1) in 1936, while the Grenland fjords were included in 1953.

The southern area consists of skerries and mediumsized fjords. The Oslofjord (length $110 \mathrm{~km}$ ) is strongly influenced by a sill located at $19 \mathrm{~m}$ depth close to Drobak (see Fig. 1) which acts as a natural barrier against replacement of the water of the inner basins. Thus, the bottom water layers are only replaced every 6 to 8 yr (Andersen et al. 1970). The outer part of the Oslofjord is, in contrast, characterised by extensive exchanges with the Skagerrak and also by anthropogenic pollutants due to industry (especially on the western side, i.e. Holmestrand, Fig. 1). The Fredrikstad area is influenced by outflow of the largest river in Norway, Glomma, on the eastern side (Fredrikstad, Fig. 1).

The study period includes 1988, during which year an exceptional toxic algae bloom took place in the spring and affected the entire Skagerrak ecosystem 
(Underdal et al. 1989, Johannessen \& Gjøsæter 1990, Granéli et al. 1993). The Chrysocromulina polylepis bloom killed most fish and many other organisms in the upper $20 \mathrm{~m}$ along large parts of the Skagerrak coast from May to June 1988 (Johannessen \& Gjøsæter 1990, Granéli et al. 1993). The algae-induced mortality had a strong effect on older year classes of cod, even though larger fish were able to migrate to greater depths (Julliard et al. 1999)

Sampling protocols. The Flodevigen data set consists of beach seine catches from more than 250 stations along the Norwegian Skagerrak coast and Oslofjord area (about 100 are still being sampled). Sampling occurs each year in September/October in accordance with the same standardised program which has been implemented since 1919 (for details, see Johannessen \& Sollie 1994, Fromentin et al. 1997b, Stenseth et al. 1999).

In parallel to the fauna survey, a hydrographic survey program was started in 1927 which sampled oxygen content, temperature and salinity at up to 144 fixed stations during the same period of the year (Johannessen \& Dahl 1996).

Selection of species. The Flødevigen monitoring data includes a total of 59 species and groups of species. In order to be consistent from a taxonomic point of view, non-fish species and groups have been excluded, leaving a total of 34 fish species, of which abundance data were available for 21 (Table 1), while only categorical data were available for the remaining 13 with 6 classes from ' 0 ' (implying no individuals) to ' 5 ' (implying very high abundance). All 34 fish species were included in the analyses of spatio-temporal patterns of fish species richness. The 21 species with abundance recordings were taken into consideration in the analysis of spatio-temporal patterns of total abundance and of the Shannon diversity index.

Selection of stations. Our analyses cover the 1953 to 1997 period, i.e. when the monitoring of the Grenland fjords started, an area with an assumed strong anthropogenic impact from industry. A total of 69 fish sampling stations that were monitored continuously throughout the period were included, located from slightly west of Kristiansand to Fredrikstad (Fig. 1). The mean number of species ranges from $3.98(\mathrm{SD}=2.01$ ) at one of the Grenland fjord stations to $9.55(\mathrm{SD}=2.35$ ) at one of the Flødevigen stations (Fig. 2).
Measurements at 27 oxygen saturation, temperature and salinity stations at 0,10 and approximately $50 \mathrm{~m}$ depth (30 to $35 \mathrm{~m}$ depth for 3 stations) were taken to detect relationships with the patterns of fish diversity (Fig. 1, hydrographic stations marked with a ' $z$ '). These measurements cover the 1953 to 1994 period. There were $5.2 \%$ missing values in the environmental data sets. These values were estimated as: value $_{\mathrm{est}}=$ mean value variable, year $\times r_{\text {varrable, slation }}+$ noise, where the relative value of each variable at a station, $r_{\text {variable, station, was calculated as mean value variable, sta- }}$

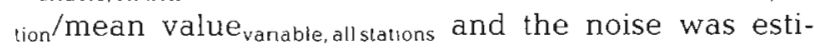
mated by a number drawn randomly from a normal distribution with expected value of the standard deviation of the variable at the station. This will ensure a neutral contribution to spatial and temporal patterns.
Table 1. Species included in this analysis of the 'Fladevigen protocol' Taxonomy according to The Integrated Taxonomic Information System (ITIS) at web-site http://www itis usda.gov/itis/index.html. The fish species have been sampled by beach seines each autumn since 1919

\begin{tabular}{|c|c|}
\hline Common name & Latin name \\
\hline \multicolumn{2}{|c|}{ Fish species with numerical counts ( 21 species) } \\
\hline Cod & Gadus morhua Linnaeus, 1758 \\
\hline Whiting & Merlangius merlagus (Linnaeus, 1758) \\
\hline Saithe (pollock) & Pollachius virens (Linnaeus, 1758) \\
\hline Pollack & Pollachius pollachius (Linnaeus, 1758) \\
\hline Sea trout & Salmo trutta Linnaeus, 1758 \\
\hline Eel & Anguilla anguilla (Linnaeus, 1758) \\
\hline Ballan wrasse & Labrus bergylta Ascanius, 1767 \\
\hline Haddock & Melanogrammus aeglefinus (Linnaeus, 1758) \\
\hline Mackerel & Scomber scombrus Linnaeus, 1758 \\
\hline Plaice & Pleuronectes platessa (Linnaeus, 1758) \\
\hline Lemon sole & Microstomus kitt (Walbaum, 1792) \\
\hline Turbot & Scophthalmus maximus (Linnaeus, 1758) \\
\hline Brill & Scophthalmus rhombus (Linnaeus, 1758) \\
\hline Norwegian topknot & Phrynorhombus norvegicus (Guenther, 1862) \\
\hline Common topknot & Zeugopterus punctatus (Bloch 1787) \\
\hline Sole & Solea vulgaris (Quensel, 1806) \\
\hline Cuckoo wrasse & Labrus bimaculatus (Linnaeus, 1758) \\
\hline Dragonet & Callionymus lyra Linnaeus, 1758 \\
\hline Armed bullhead & Agonus cataphractus Linnaeus, 1758 \\
\hline Rock gunnel & Pholis gunnellus (Linnaeus, 1758) \\
\hline Grey gurnard & Eutrigla gurnardus (Linnaeus, 1758) \\
\hline \multicolumn{2}{|c|}{ Fish species with categorical counts ( 13 species) } \\
\hline Herring & Clupea harengus Linnaeus, 1758 \\
\hline Sprat & Sprattus sprattus (Linnaeus, 1758) \\
\hline Horse mackerel & Trachurus trachurus (Linnaeus, 1758) \\
\hline Flounder & Platichthys flesus (Linnaeus, 1758) \\
\hline $\mathrm{Dab}$ & Limanda limanda (Linnaeus, 1758) \\
\hline Long rough dab & Hippoglossoides platessoides (Fabricius, 1780) \\
\hline Goldsinny wrasse & Ctenolabrus rupestris (Linnaeus, 1758) \\
\hline Corkwing wrasse & Crenilabrus melops (Linnaeus, 1758) \\
\hline Rock cook & Centrolabrus exoletus (Linnaeus, 1758) \\
\hline Threespine stickleback & Gasterosteus aculeatus Linnaeus, 1758 \\
\hline Fifteenspine stickleback & Spinachia spinachia (Linnaeus, 1758) \\
\hline Poor cod & Trisopterus minutus (Linnaeus, 1758) \\
\hline Viviporous eelpout & Zoarces viviparus Linnaeus, 1758 \\
\hline
\end{tabular}




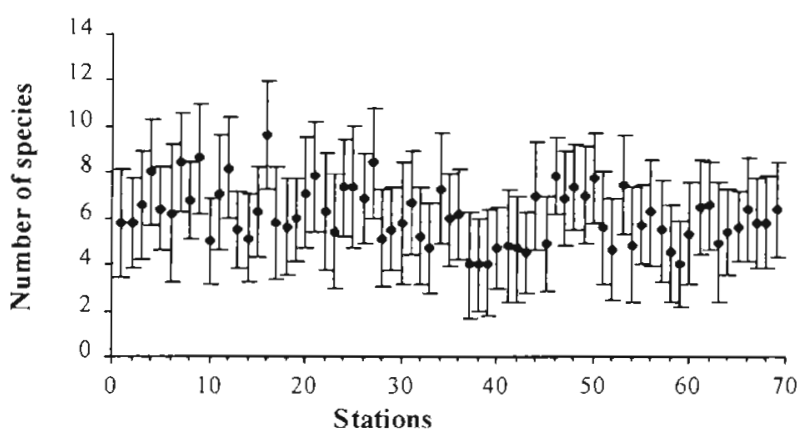

Fig. 2. Mean number of species with associated standard deviation at stations from 1953 to 1997 . Low-numbered stations are located in the southwest (lower left-hand section of Fig. 1, while the higher numbers are located in the northeast (upper right-hand section of Fig. 1)

Table 2. Total mean values and associated standard deviations of environmental variables for 27 stations along the Skagerrak coast (cf. Fig. 1) 1953 to 1994

\begin{tabular}{lccc|}
\hline Variable & Sea surface & $\begin{array}{c}10 \mathrm{~m} \\
\text { depth }\end{array}$ & $\begin{array}{c}50(30-35) \mathrm{m} \\
\text { depth }\end{array}$ \\
\hline $\begin{array}{l}\text { Oxygen } \\
\text { saturation (\%) }\end{array}$ & $97.7 \pm 12.2$ & $89.7 \pm 14.7$ & $63.0 \pm 13.0$ \\
Salinity $(\%)$ & $21.9 \pm 5.3$ & $29.5 \pm 2.6$ & $33.4 \pm 0.6$ \\
Temperature $\left({ }^{\circ} \mathrm{C}\right)$ & $12.9 \pm 1.3$ & $13.7 \pm 1.1$ & $9.3 \pm 1.5$ \\
\hline
\end{tabular}

There was large variability in the environmental data (Table 2), with evidence of anoxia and unstable temperatures at the bottom (Fig. 3a,b) and outflow of fresh water to the Grenland fjords at the sea surface (Stns 16 to 18 in Fig. 3c) and less saline water to the east (Fig. 3c).

\section{ANALYSES}

The total abundance data of each station each year (plus a constant of 1) were ln-transformed to stabilise the variance (Sokal \& Rohlf 1995). As we were mainly interested in the long-term variability, the time series of the number of species were smoothed using Eigen Vector Filtering (EVF; see e.g. Ibanez \& Etienne 1991, Fromentin et al. 1997a). EVF, which is based on the Principle Components Analysis (PCA) of the autocovariance matrix of the given time series, was used taking into account a lag of 3 yr. EVF displayed, on the first axes, the main temporal patterns of variation of a given time series, e.g. trend, seasonal cycle or year-toyear variation, together with the percent of variance. In our case, 51 time series displayed clear long-term trends whereas the 18 remaining series mainly exhib-

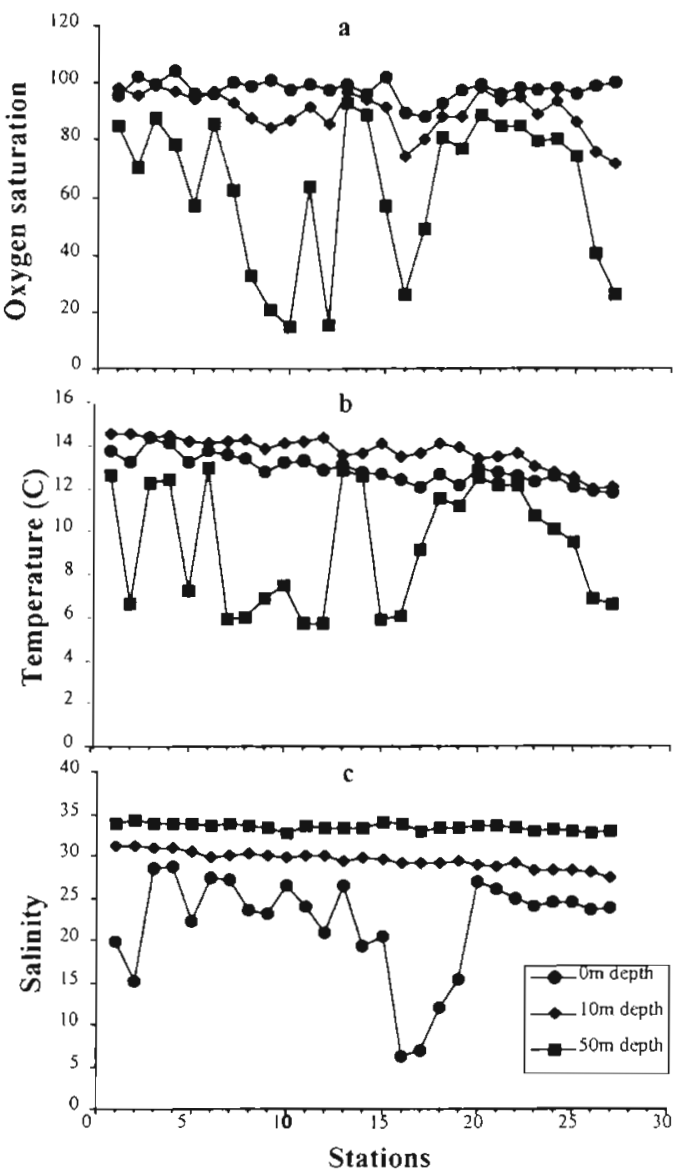

Fig. 3. Environmental variables at stations at 0,10 , and $50 \mathrm{~m}$ depth (30 to $35 \mathrm{~m}$ for Stns 4, 9, and 10), mean 1953 to 1994 (a) Oxygen saturation in \%. (b) Temperature in ${ }^{\circ} \mathrm{C}$. (c) Salinity in $\%$

ited year-to-year fluctuations. We have chosen this smoothing technique rather than the moving average (MA) or lowess techniques because the former led to loss of the borders and the latter to filtering which was too low.

In order to extract the dominant patterns in the temporal dynamics across all stations and subsections of the monitoring transect, PCA (e.g. Legendre \& Legendre 1983) was performed on the covariance matrices, using the stations as descriptors (years as rows, stations as columns). This procedure was applied to the species richness, total species abundance and the Shannon diversity index (Magurran 1988). A PCA summarises the variability of the descriptors in a lower number of dimensions than the original observations (i.e. the principal axes, see Legendre \& Legendre 1983). As is commonly done in similar studies (e.g. Fromentin et al. 1997b, 1998), sampling variance is not taken into account. However, PCA is a descriptive tool, so sampling errors are likely to have much less influence on the results than is the case for most statistical 
procedures, which implies inference. The first axis of the PCA, which takes into account the largest fraction of the variance of the matrix years by stations, displays in our case the main spatial pattern of temporal variations of the species richness and diversity (Legendre \& Legendre 1983, Manly 1994). The second axis corresponds to the next largest proportion of variance, and so on. By checking the column scores of the stations, we get the contribution of the various stations among the PCA axes and thus the spatial patterns.

Relationships between the number of species (of a total of 34) and the 9 hydrographic variables at 27 stations (cf. Fig. 1) were investigated by means of correlation analysis using the Pearson correlation coefficient (taking autocorrelation into account, see e.g. Priestley 1981). The correlation coefficients were computed between the mean raw time series, detrended time series (by a first order differencing), and EVF time series (e.g. the trends). When the first order autoregressive term was significant, sample size was adjusted by the factor $\left(1-\alpha_{1} \alpha_{2}\right) /\left(1+\alpha_{1} \alpha_{2}\right)$, where $\alpha_{1}$ and $\alpha_{2}$ are the first autocorrelation coefficients of the 2 time series being compared, to account for autoregressive processes (Priestley 1981).

\section{RESULTS}

\section{PCA of the number of species}

For the 69 stations being monitored from 1953 to 1997, the first 3 axes of the PCA on the number of species, smoothed by EVF, using the stations as descriptors, accounted for $46.4 \%$ of the total variance. This rather low percentage of variance explained by the PCA was an effect of large spatial variability. The first principal axis of the PCA (i.e. the main temporal pattern which took into account $20.8 \%$ of the variance), exhibited a decrease in the number of species during the period, stabilising towards the end of the period (Fig. 4a).

An examination of the column scores of the various stations with the first axis reveals a difference between the Oslofjord area and the rest of the stations (Fig. 4d). Most of the stations that are highly correlated with the first axis were located to the east of the Skagerrak coast, especially those of the Oslofjord area (i.e. righthand side in Fig. 4d). The first axis of the PCA thus displayed a temporal pattern for these stations (Fig. 4a). The second axis explained $15.0 \%$ of the variations in temporal patterns, and exhibited an early decrease fol-
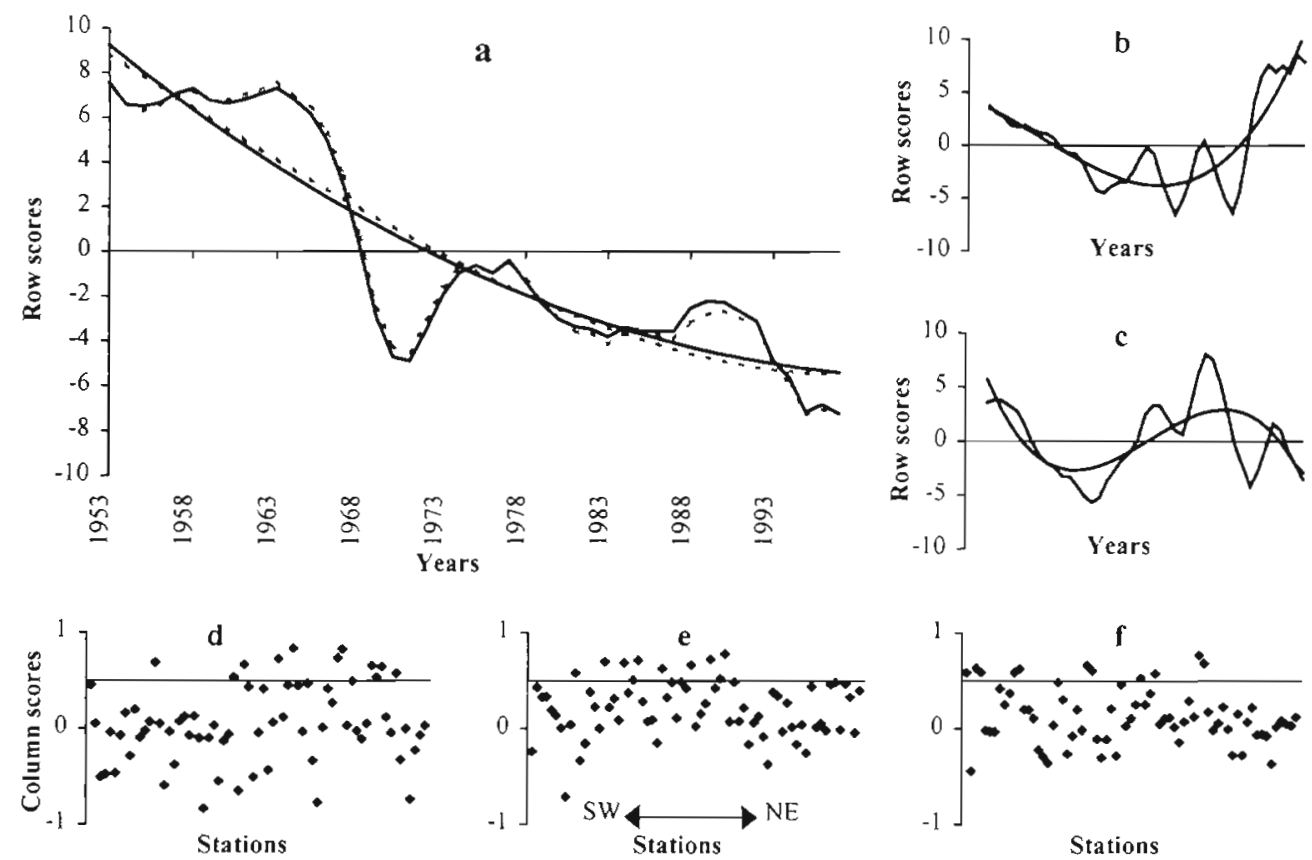

Fig. 4. Principle Components Analysis (PCA) of the number of species at 69 stations along the southern coast of Norway 1953 to 1997. 34 species were included (see Table 1 for a species list). The time series were smoothed by Eigen Vector Filtering (see text). (a) Solid lines: main temporal pattern (principal axis) explaining $20.8 \%$ and a third order polynomial fitted to the temporal pattern. Dashed lines: main temporal pattern with fitted line when 1988 was replaced by the mean of the 2 preceding and subsequent years. (b) Second axis temporal pattern, explaining $15.0 \%$, with a third order polynomial fitted. (c) Third axis temporal pattern, explaining $10.7 \%$, with a third order polynomial fitted. Column scores of the individual stations for the respective temporal axes for the 69 stations are displayed in panels $d$ and e. (d) 1 st axis, (e) 2 nd axis, (f) 3 rd axis. Stations that exhibit the respective patterns have high column scores $(\geq 0.5)$ for the temporal axis in question 


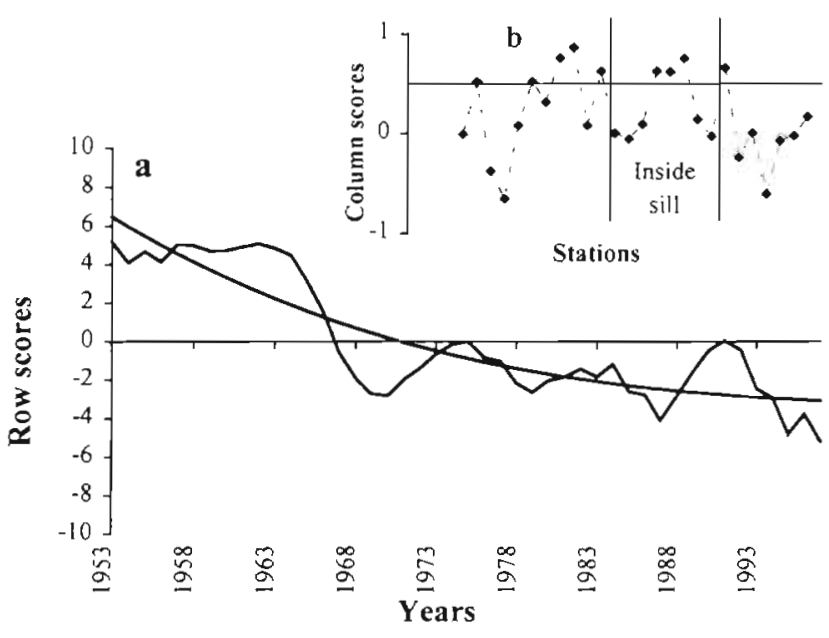

Fig. 5. PCA of the number of species in the Oslofjord 1953 to 1997 Methods and terminology as in Fig. 4. (a) Main temporal pattern explaining $26.0 \%$ and a third order polynomial fitted to the temporal pattern. (b) Column scores of the individual stations for the 1 st axis. The left-hand side stations are located on the west side of the fjord, while the right-hand side stations are located on the east side

lowed by an increase towards the end of the period (Fig. 4b). This pattern was mainly displayed by the western stations (i.e. left-hand side in Fig. 4e). The third axis explained $10.7 \%$ and displayed an early

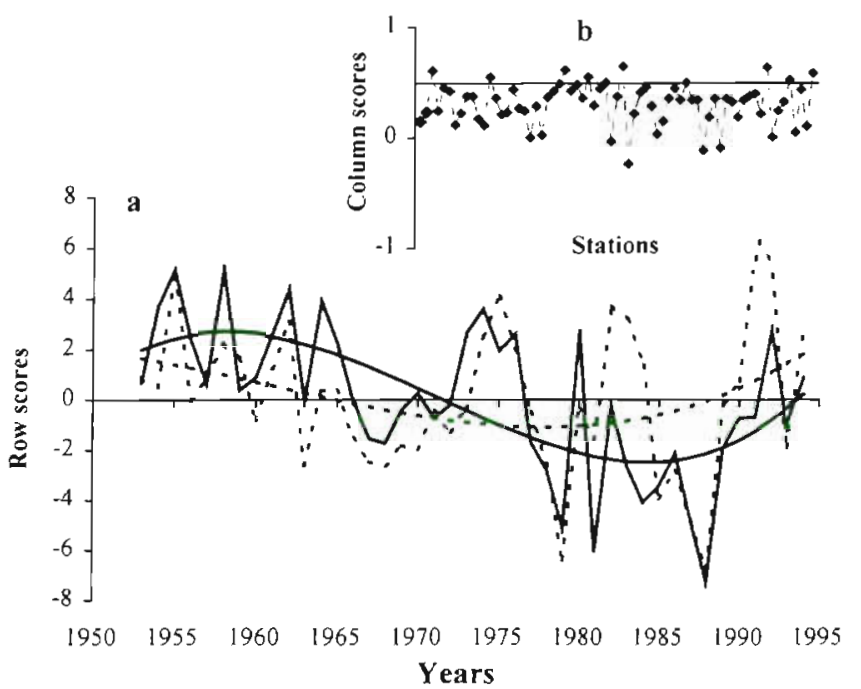

Fig. 6. PCA of the Shannon diversity index at 69 stations along the Southern coast of Norway 1953 to 1997. 21 species for which numerical counts exist were included (see Table 1 for a species list). The data were standardized by subtracting the mean and dividing by the standard deviation. (a) Solid lines: main temporal pattern (principal axis) explaining $13.1 \%$ and a third order polynomial fitted to the temporal pattern (the 2nd axis explained $6.5 \%$ and the $3 \mathrm{rd}$ axis explained $5.9 \%$ ). Dashed lines: main temporal pattern with polynomial fit for the standardized number of species. (b) Column scores of the individual stations for the 1st temporal axes for the 69 stations decrease, followed by an increase towards the mid 1980 s and a decrease towards the end of the period studied (Fig. 4c). However, there was no systematic spatial pattern (Fig. 4f).

Prompted by the spatial division in the previous analysis, a separate PCA of the Oslofjord area revealed further details of the spatial patterns. The main temporal pattern was basically the same as the pattern found for the whole coast, although more dominant for the Oslofjord area than for the whole coast $26.0 \%$ of the variation explained compared to $20.8 \%$, compare Fig. $4 \mathrm{a}$ and Fig. 5a). As can be seen from the column scores of Fig. 5b, stations located both outside and inside the sill at $19 \mathrm{~m}$ depth close to Drøbak in the middle of the fjord (see Fig. 1) display high column scores, thus displaying this temporal pattern (Fig. 5b).

In summary, 2 main temporal patterns of species richness of fish assemblages along the Norwegian Skagerrak coast emerged: The temporal pattern in the Oslofjord area, which included some stations both inside and outside the sill at Drobak, displayed a decrease in the number of species throughout the study period (Fig. 4a). Outside the Oslofjord area there was a decreasing trend until the early 1980 s followed by a increase throughout the 1990s (Fig. 4b).

\section{PCA of the Shannon diversity index}

Since the Shannon diversity index requires information on abundance, this index was calculated for the 69 stations using only the data on the 21 species for which numerical counts (i.e. abundance data) were available. The PCA of the Shannon diversity index gave results similar to those for the number of species (Fig. 6a, solid line). The main temporal patterns of the Shannon diversity index and the species number had a correlation coefficient of 0.64 and of 0.65 when the time series were detrended by a first order differencing. However, the amount of variation explained by the PCA of the Shannon diversity index was low (only $25 \%$ for the first 3 axes), thus indicating large spatial variability. Furthermore, the analysis of the Shannon diversity index failed to reveal any spatial patterns (Fig. 6b).

\section{PCA of abundance}

The 3 first axes of the PCA on abundance data encompassed approximately $34.4 \%$ of the total variance. The first axis (19.0\% of the total variance) displayed a decline from the early 1960 s, followed by a slight increase in the 1990s (Fig. 7a, solid line). This pattern was not significantly correlated with the pattern displayed for the number of species (correlation 


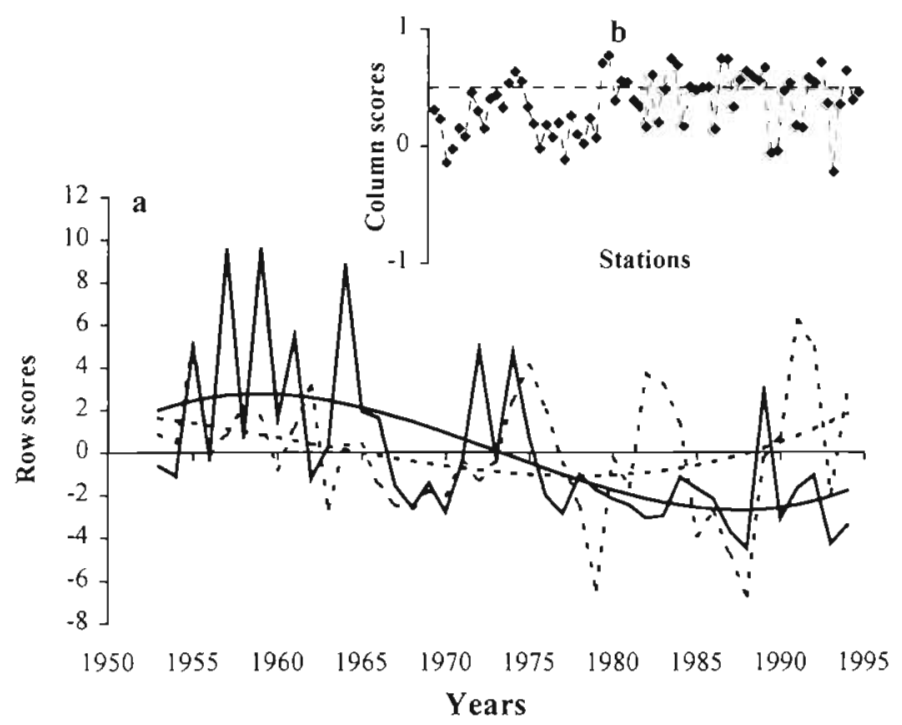

Fig. 7 PCA of abundance at 69 stations along the southern coast of Norway 1953 to 1997. 21 species for which numerical counts exist were included (see Table 1 for a species list). The data were in-transformed and standardized by subtracting the mean and dividing by the standard deviation. (a) Main temporal pattern (principal axis) explaining 19.0\% and a third order polynomial fitted to the temporal pattern (the 2nd axis explained $8.8 \%$ and the $3 \mathrm{rd}$ axis explained $6.6 \%$ ). Dashed lines: main temporal pattern with polynomial fit for the standardized number of species. (b) Column scores of the individ-

ual stations for the 1 st temporal axes for the 69 stations

coefficient of 0.26 ). There was no clear systematic spatial division of the temporal pattern, although the row scores were somewhat higher to the east (Fig. 7b). No further spatial patterns were found for the second or third axis of the PCA (not shown).

\section{Correlation between number of species and hydrographic variables}

The correlation coefficients between the means of the standardised time series ('regular'), detrended ones (obtained by the first order difference) and the trends alone (obtained by EVF filtering) of the number of species and the 9 hydrographic variables are shown in Table 3. Oxygen saturation at the sea surface, temperature at the sea surface and $10 \mathrm{~m}$ depth and the number of species displayed similar temporal fluctuations (Fig. 8). These 3 variables showed significant (at the 0.05 level, $n=42$ ) correlation coefficients for the regular time series, while oxygen saturation was significant only at the 0.1 level for the detrended time series. For the EVF-filtered series, none of the variables showed significant correlation coefficients at the 0.05 level, but oxygen saturation at the sea surface and temperature at $10 \mathrm{~m}$ depth were correlated with the number of species at the 0.1 level.

\section{DISCUSSION}

\section{Processes generating temporal patterns at a regional scale}

The rather distinct temporal pattern of fish richness of the Oslofjord area compared to the rest of the coast is not particularly surprising (see e.g. Mirza \& Gray 1981, Nash 1985). However, that this rather distinct pattern includes stations both inside and outside the sill at Drøbak (see Fig. 1) is somewhat surprising and suggests that processes overriding the spatial barrier of the sill were important in generating the observed patterns. Since the main temporal pattern of the Oslofjord area was also displayed by stations outside the barrier, some properties of the Skagerrak waters seem to be preserved ( 5 of 11 stations on the west side, and 1 of 6 on the east side of the Oslofjord display high column scores with the main temporal pattern, Fig. 5b). This is consistent with Roughgarden et al. (1994), who pointed out that causes of population fluc-
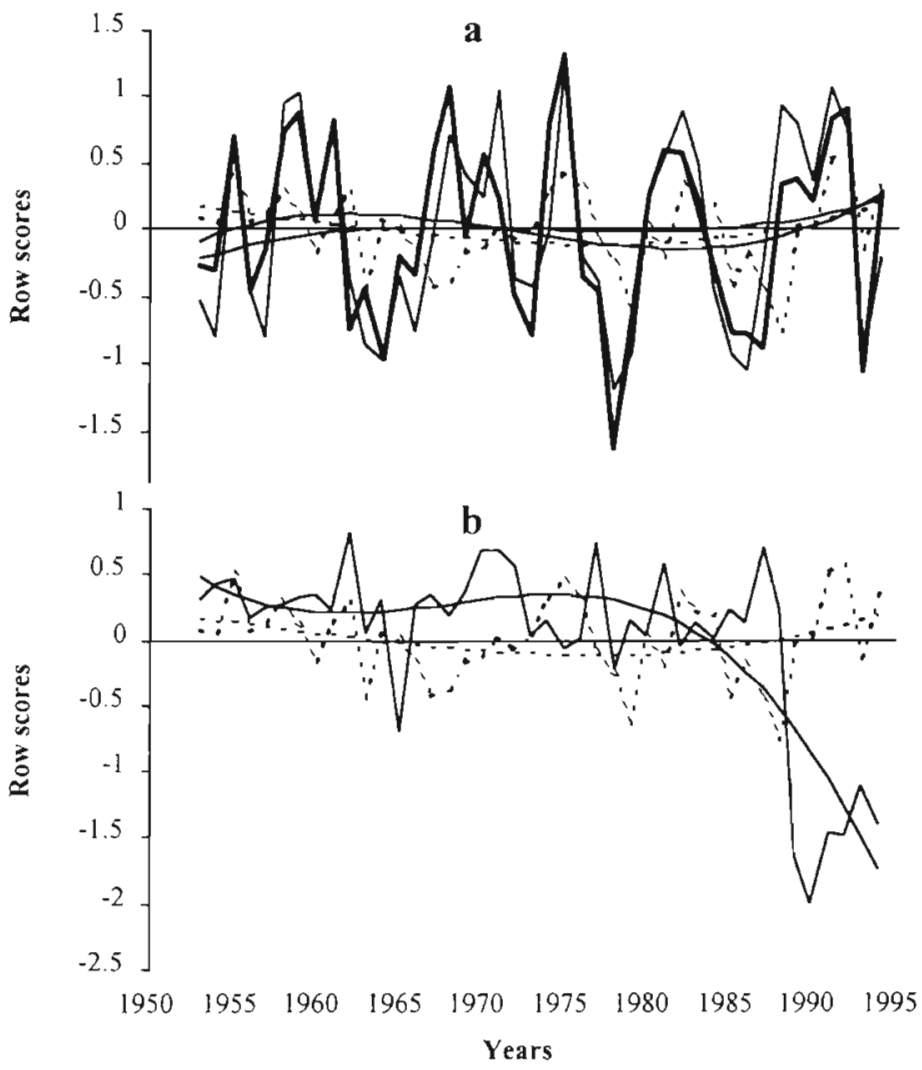

Fig. 8. Standardized mean time series for 69 fauna and 27 hydrographic stations by years 1953 to 1994 (see Fig. 1 for locations). (a) Temperature at sea surface (regular lines) and $10 \mathrm{~m}$ depth (bold lines) and the number of species (dashed lines). (b) Oxygen saturation at the sea surface and the number of species (dashed lines) 
Table 3. Correlation coefficients between the mean time series of the number of species (cf. Fig. 1, maximum of 34 species) and the mean time series of 9 hydrographic variables 1953 to 1994. The first column displays the correlation coefficients between the number of species and environmental variables for unmanipulated time series, the second column for time series detrended by 1st order differencing, and the third for Eigen Vector Filtering (EVF) smoothed series. $n=42$ yr. ${ }^{*} p<0.05,{ }^{\dagger} p<0.1$

\begin{tabular}{|c|c|c|c|}
\hline \multirow[t]{2}{*}{ Variable } & \multicolumn{3}{|c|}{ Correlation coefficients with the number of species } \\
\hline & Regular time series & Detrended time series & EVF-filtered series \\
\hline Oxygen saturation at $0 \mathrm{~m}$ depth & $-0.3117^{\bullet}$ & $-0.2731^{+}$ & $-0.2834^{\dagger}$ \\
\hline Oxygen saturation at $10 \mathrm{~m}$ depth & -0.0363 & 0.1438 & -0.0514 \\
\hline Oxygen saturation at $50 \mathrm{~m}$ depth & -0.039 & -0.0797 & 0.0864 \\
\hline Salinity at $0 \mathrm{~m}$ depth & -0.1065 & 0.0156 & -0.2155 \\
\hline Salinity at $10 \mathrm{~m}$ depth & -0.0475 & 0.0845 & -0.1156 \\
\hline Salinity at $10 \mathrm{~m}$ depth & 0.0419 & -0.1615 & 0.3054 \\
\hline Temperature at 0 m depth & $0.3455^{\circ}$ & $0.4498^{\circ}$ & 0.176 \\
\hline Temperature at $10 \mathrm{~m}$ depth & $0.4006^{\circ}$ & $0.3554^{\circ}$ & $0.3401^{f}$ \\
\hline Temperature at $50 \mathrm{~m}$ depth & 0.0579 & 0.0770 & -0.0871 \\
\hline
\end{tabular}

tuations in marine coastal systems might be found in the open ocean. Indeed, the abundance of Calanus finmarchicus, which constitutes the main food supply of fish larvae of several species (Cushing 1982), has declined in the Northeast Atlantic and adjacent seas since the 1970 s (Fromentin \& Planque 1996, Planque \& Fromentin 1996). As the waters of the Northeast Atlantic are transported to the Skagerrak area by several currents and along the coast by the Norwegian Coastal current (see Danielssen et al. 1997), these changes potentially might have affected the fish dynamics and diversity in coastal populations (Mann \& Lazier 1991). Specifically, advection of zooplankton. from the open waters into the fjords might be the process responsible (Aksnes et al. 1989, Giske et al. 1991, Kaartvedt 1991). It has been shown that advective processes were the major factor regulating abundance of Calanus spp. in the Gullmar fjord just south-east of our study area (Lindahl \& Hernroth 1988). The same phenomenon has been observed in the Oslofjord during autumn (E. Bagøien pers. comm.).

The observed regional pattern may also be due to the development of industry and the input of nutrients from Norway and other European countries (cf. currents coming from the Baltic Sea and the German Bight). Johannessen \& Dahl (1996) have investigated the water transparency between 1960 and 1993 and found this to be low both in the inner Oslofjord area and in the Grenland area (cf. Fig. 1). Furthermore they showed that the input of nutrients from industry and sewage reached a maximum in the Grenland area around 1970.

The lowest number of species (mean 4.5, $\mathrm{SD}=2.5$ ) was observed in 1988, the year of the toxic algae bloom (see e.g. Fig. 1 in Underdal et al. 1989). However, this year did not have a strong effect on the overall temporal pattern, as the recovery of the number of species seemed to start before 1988 (Fig. 4b). It makes no dif- ference to the temporal pattern if 1988 was replaced by an average of the 2 preceding and 2 subsequent years (correlation coefficient 0.99, Fig. $4 \mathrm{a}$, dashed line). Thus, there seems to be no long-lasting effects of the algal bloom on the number of fish species in these fish assemblages.

\section{Processes generating temporal patterns at a local scale}

An explanation of local variation in the observed temporal patterns may be related to variation in plankton composition. However, since we have no simultaneous data on plankton, we used oxygen saturation as an indicator of past plankton abundance, and a possible indicator of eutrophication due to pollution. With increased nutrient load, organic matter production increases and a subsequent degradation of this organic matter leads to reduced oxygen saturation (Rosenberg 1985, Rydberg et al. 1990). Low values of oxygen saturation could thus be interpreted as the footprints of high abundance of plankton, which will supply abundant prey for several fish species in the coastal community. However, low levels of oxygen saturation also have negative effects on survival and biological interactions for several species (Breitburg et al. 1997, Fraser 1997. Kiceniuk \& Colbourne 1997). In this study oxygen saturation was negatively associated with the number of species, i.e. low values of oxygen saturation were associated with high levels of species richness. The indirect, positive effect of rich prey abundance thus seemed to outweigh the negative effects. This runs counter to the findings of Fraser (1997), which showed a positive relationship between oxygen content and the number of species in a study spanning 13 yr. Oxygen saturation at all 3 depths showed a decline towards the end of the study period, possibly producing an impact in the future. 
Temperature at 0 and $10 \mathrm{~m}$ depth were significantly associated with the number of species both for the yearto-year fluctuations and the detrended series (Table 3 , Fig. 8a). The effect of temperature on temporal variation has been demonstrated by Clark and co-workers in a 2 yr study (Clark et al. 1996) and by Fraser in a 13 yr study (Fraser 1997). As fish species have a thermal preference, changes in temperature will affect food consumption, growth and reproduction rates. The effects may be direct, or indirect as a result of changes in patterns of interactions (Wootton 1990) or in prey abundance. More species were caught when the temperature increased. This result can be due to competitive release if dominant species are negatively correlated with temperature, but could also be due to general positive relationships between abundance and temperature. We do not know the exact competitive relationships between the different species, but the most abundant species, cod and whiting, were both positively associated with temperature at $10 \mathrm{~m}$ depth (not shown). Thus we find the latter explanation more probable, as has also been suggested by Rogers \& Millner (1996).

The spatial difference between the Oslofjord area and the rest of the coast might also be explained by the colder waters in the inner Oslofjord (i.e to the right in Fig. $3 b)$ as the mean species richness was somewhat lower in the Oslofjord area $(5.9, \mathrm{SD}=2.3)$ than for the rest of the coast $(6.2, \mathrm{SD}=2.6)$. Large-scale processes such as the North Atlantic Oscillation (NAO; Hurrell 1995) probably generate the temperature patterns of the Skagerrak coast and large-scale currents (Fromentin et al. 1998).

Most of the species in this investigation are demersal species, and therefore potentially influenced by substrate type and quality (Tupper \& Boutilier 1995). We are not aware of data on substrate of the same spatial resolution and temporal extent as the fish data. How ever, a very crude characterisation of the bottom coverage exists (1 data point determined by eye each year presentation of these data can be found in Fromentin et al. 1998). Initial correlation analysis between the pattern of bottom coverage and the mean time series of the number of species did not give any significant results (correlation coefficient $-0.04, \mathrm{n}=41 \mathrm{yr}$ ).

\section{Abundance, diversity indices and species number}

Both the Shannon diversity index and abundance failed to display distinct spatial patterns of temporal variation. The main temporal pattern of abundance was not significantly associated with the main temporal pattern of the number of species. As the Shannon diversity index incorporates both abundance and evenness, the discrepancy in temporal patterns between abundance and the number of species might blur patterns in the Shan- non diversity index. Total abundance and the number of species thus undergo slightly different temporal and spatial processes (Fig. 7). This is in agreement with the intermediate disturbance hypothesis (Caswell 1976 , Connell 1978). According to this hypothesis, low disturbance will enable a community to reach equilibrium and enhance competitive exclusion of species, and high disturbance will exclude species because of low rate of survival and colonisation ability. The number of species will thus reach a maximum at intermediate levels of disturbance, while high total abundance is possible at low, intermediate and high numbers of species. We believe that the investigated communities range from severely disturbed (i.e. the Oslofjord area [Nash 1985] and the industrialised areas [Johannessen \& Dahl 1996]) to intermediate levels of disturbance (the remaining stations). In addition, the Southern coast of Norway is subjected to recreational and professional fishing, which contribute considerably to mortality (Julliard et al. 1999). The observed spatial patterns of temporal variation thus seem to reflect ecological processes.

\section{CONCLUSION}

Our analyses reveal 2 main temporal patterns of fish species diversity along the Norwegian Skagerrak coast, separating the Oslofjord area and the rest of the Skagerrak coast. There has been a recovery in the number of species for the southern part of the open Skagerrak coast, while the Oslofjord area has not experienced such a recovery.

The spatial scale of this temporal variation in fish species diversity (number of species) exceeds the scale of the fjord. Temporal patterns explaining a considerable part of the variation in the Oslofjord area include stations both outside and inside the sill in the middle of the fjord. This points to processes at a regional scale regulating fish species diversity. Although these processes have not been thoroughly investigated, on the basis of these findings, we cannot expect local management strategies for enhancing diversity to be sufficient; measures to enhance biodiversity must take regional processes into consideration.

Acknowledgements. Our appreciation goes to the late Rangvald Løversen and to Aadne Sollie for carrying out the sampling resulting in the 'Flodevigen data set' Thanks are due to a project funded by the Directorate for Nature Conservation (DN) for organising the data into computer-readable format. Financial support from the University of Oslo (through the 'Environmental Program' to N.C.S.), from the MAST-program of the European Union (fellowship contract to J.M.F.), and the Norwegian Science Council (NFR; to N.C.S. for supporting K.L.) made the reported analyses possible. Thanks go to Thierry Boulinier and 4 anonymous reviewers for useful comments on an earlier version of the paper 


\section{LITERATURE CITED}

Aksnes DL, Aure J, Kaartvedt S, Magnesen T, Richard J (1989) Significance of advection for the carrying capacities of fjord populations. Mar Ecol Prog Ser 50:263-274

Andersen T, Beyer F, Foyn E (1970) Hydrography of the Oslofjord. Report on the study course in chemical oceanography arranged in 1969 by ICES with support of UNESCO. ICES (Int Counc Explor Sea) Coop Res Rep 20: $1-62$

Bøhle B (1993) S\&rbare fiskeressurser i Skagerrak. Rapp forskningsstasjonen Flødevigen 1993:1-23

Botsford LW, Castilla JC, Peterson $\mathrm{CH}$ (1997) The management of fisheries and marine ecosystems. Science 277: 509-515

Breitburg DL, Loher T, Pacey CA, Gerstein A (1997) Varying effects of low dissolved oxygen on trophic interactions in an estuarine food web. Ecol Monogr 67:489-507

Caswell H (1976) Community structure: a neutral model analysis. Ecol Monogr 46:327-354

Clark BM, Bennet BA, Lamberth SJ (1996) Temporal variation in surf zone fish assemblages from False Bay, South Africa. Mar Ecol Prog Ser 131:35-47

Clarke KR, Green RH (1988) Statistical design and analysis for a 'biological effects' study. Mar Ecol Prog Ser 46: $213-226$

Connell JH (1978) Diversity in tropical rain forests and coral reefs. Science 199:1302-1310

Cushing DH (1982) Climate and fisheries. Academic Press, London

Danielssen DS, Edler L, Fonselius S, Hernroth L, Ostrowski M, Svendsen E, Talpsepp L (1997) Oceanographic variability in the Skagerrak and northern Kattegat, May-June, 1990. ICES J Mar Sci 54:753-773

Dickson RR (1971) A recurrent and persistent pressure-anomaly pattern as the principal cause of intermediate-scale hydrograpic variation in the European shelf seas. Dtsch Hydrogr Z 24:97-119

Dickson RR, Briffa KR, Osborn TJ (1994) Cod and climate: the spatial and temporal context. ICES Mar Sci Symp 198: $280-286$

Fraser TH (1997) Abundance, seasonality, community indices, trends and relationships with physicochemical factors of trawled fish in upper Charlotte Harbor, Florida. Bull Mar Sci $60: 739-763$

Fromentin JM, Planque B (1996) Calanus and environment in the eastern North Atlantic. II. Influence of the North Atlantic Oscillation on C. finmarchicus and C. helgolandicus. Mar Ecol Prog Ser 134:111-118

Fromentin JM, Ibanez F, Dauven JC, Dewarumez JM, Elkaim B (1997a) Long-term changes of four macrobenthic assemblages from 1978 to 1992. J Mar Biol Assoc UK 77. $287-310$

Fromentin JM, Stenseth NC, Gjøsæter J, Bjørnstad ON, Falck W, Johannessen $T$ (1997b) Spatial patterns of the temporal dynamics of three gadoid species along the Norwegian Skagerrak coast. Mar Ecol Prog Ser 155:209-222

Fromentin JM, Stenseth $N C$, Gjøsæter $J$, Johannessen $T$, Planque B (1998) Long-term fluctuations in cod and pollack along the Norwegian Skagerrak coast. Mar Ecol Prog Ser 162:265-278

Gibson RN (1982) Recent studies of the biology of intertidal fishes. Oceanogr Mar Biol Annu Rev 20:363-414

Giske J, Aksnes DL, Lie U. Wakili SM (1991) Computer simulation of pelagic production in Masfjorden, western Norway, and its consequences for production of released 0-group cod. ICES Mar Sci Symp 192:161-175
Gjesæter J (1988) Competition for food and predator-prey relationships among young cod (Gadus morhua) and some other fish from shallow waters. Fladevigen Rapp 1:1-15

Granéli E, Paasche E, Maestrini SY (1993) Three years after the Chrysochroulina polylepis bloom in Scandinavian waters in 1988: some conclusions of recent research monitoring. In: Smayda TJ, Shimizu Y (eds) Toxic phytoplantkon blooms in the sea. Proceedings of the 5th international conference on toxic phytoplankton, Newport, R.I. 28 October-1 November, 1991. Elsevier, Amsterdam, p 25-32

Hurrell JW (1995) Decadal trends in the North Atlantic Oscillation: regional temperatures and precipitation. Science 269:676-679

Ibanez F, Etienne $M$ (1991) Le filtrage des séries chronologiques par l'analyse en composantes principales de processus. J Rech Océanogr 16:66-72

Johannessen T, Dahl E (1996) Declines in oxygen concentrations along the Norwegian Skagerrak coast, 1927-1993: a signal of ecosystem changes due to eutrophication? Limnol Oceanogr 41:766-778

Johannessen T, Gjøsæter J (1990) Algeoppblomstringen i Skagerrak i mai 1988-ettervirkninger på fisk og bunnfauna langs Sorlandskysten. Flodevigen Meldinger 6:1-68 (in Norwegian)

Johannessen T, Sollie A (1994) Overvåking av gruntvannsfauna på Skagerrakkysten. Fisken Havet 10:1-91 (in Norwegian)

Julliard R, Stenseth NC, Gjøsæeter J, Lekve K, Fromentin JM, Danielssen DS (1999) Natural and fishing morality in a cod population along the Norwegian Skagerrak coast: a release-recapture experiment. Ecol Appl (in press)

Kaartvedt S (1991) Plankton as potential prey in fjords. ICES Mar Sci Symp 192:156-160

Kiceniuk JW, Colbourne E (1997) Relating oxygen levels in the Newfoundland offshore waters to the physiology of Atlantic cod (Gadus morhua). Can J Fish Aquat Sci 54: $81-87$

Legendre L, Legendre P (1983) Numerical ecology. Elsevier, Amsterdam

Lindahl O, Hernroth L (1988) Large-scale and long-term variation in the zooplankton community of the Gullmar fjord, Sweden, in relation to advective processes. Mar Ecol Prog Ser 43:161-171

Magurran AE (1988) Ecological diversity and its measurement. Croom Helm, London

Manly BFJ (1994) Multivariate statistical methods. A primer Chapman \& Hall, London

Mann KH, Lazier JRN (1991) Dynamics of marine ecosystems Blackwell, Cambridge

Mirza FB, Gray JS (1981) The fauna of benthic sediments from the organically enriched Oslofjord. Norway. J Exp Mar Biol Ecol 54:181-207

Nash RDM (1985) The distribution of fish in the Oslofjord and its possible relationship to pollution. In: Gray JS, Christiansen ME (eds) Marine biology of polar regions and effects of stress on marine organisms. Proceedings of the 18th European Marine Biology Symposium. John Wiley \& Sons, Chichester, p 389-400

Planque B. Fromentin JM (1996) Calanus and environment in the eastern North Atlantic. I. Spatial and temporal patterns of C. finmarchicus and C. helgolandicus. Mar Ecol Prog Ser 134:101-109

Priestley MB (1981\} Spectral analysis of time series. Univariate series. Academic Press, London

Rangeley RW, Kramer DL (1995) Tidal effects on habitat selection and aggregation by juvenile pollock Pollachius 
virens in the rocky intertidal zone. Mar Ecol Prog Ser 126: $19-29$

Rogers SI, Millner RS (1996) Factors affecting the annual abundance and regional distribution of English inshore demersal fish populations: 1973 to 1995. ICES J Mar Sci $53: 1094-1112$

Rosenberg R (1985) Eutrophication-the future marine coastal nuisance? Mar Pollut Bull 16:227-231

Roughgarden J, Pennington T, Alexander S (1994) Dynamics of the rocky intertidal zone with remarks on generalization in ecology. Phil Trans R Soc Lond B 343:79-85

Ruud JT (1968) Changes since the turn of the century in the fish fauna and the fisheries of the Oslofjord. Helgol Wiss Meeresunters 17:510-517

Rydberg L, Edler L, Floderus S, Granéli W (1990) Interaction between supply of nutrients, primary production, sedimentation and oxygen consumption in SE Kattegat. Ambio 19:134-141

Sale PF (1988) Perception, patterns, change and the structure of reef fish communities. Environ Biol Fish 21:3-15

Editorial responsibility: Otto Kinne (Editor),

Oldendorf/Luhe, Germany
Sokal RR, Rohlf FJ (1995) Biometry. The principles and practice of statistics in biologiccal research. WH Freeman and Co, New York

Stenseth NC, Bjørnstad ON, Falck W, Fromentin JM, Gjøsæter J, Gray JS (1999) Dynamics of coastal cod populations: intra- and inter-cohort density-dependence and stochastic processes. Proc R Soc Lond B (in press)

Tupper M. Boutilier RG (1995) Effects of habitat on settlement, growth, and postsettlement survival of Atlantic cod (Gadus morhua). Can J Fish Aquat Sci 52:1834-1841

Tveite $S$ (1971) Fluctuations in year-class strength of cod and pollack in southeastern Norwegian coastal waters during 1920-1969. Fiskeridir Skr Ser Havunders 16:65-76

Underdal B, Skulberg OM, Dahl E, Aune T (1989) Disastrous bloom of Chrysochroulina polylepis (Prymnesiophyceae) in Norwegian coastal waters 1988-mortality in marine biota. Ambio 18:265-270

Wiens JA (1989) Spatial scaling in ecology. Funct Ecol 3:385-397

Wootton RJ (1990) Ecology of teleost fishes. Chapman \& Hall, London

Submitted: March 12, 1998; Accepted: November 11, 1998 Proofs received from author(s): March 9, 1999 